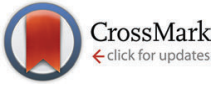

Cite this: Phys. Chem. Chem. Phys., 2015, 17, 25925

Received 3rd April 2015 Accepted 5th June 2015 DOI: $10.1039 / c 5 c p 01960 e$

www.rsc.org/pccp

\section{UV photodissociation spectroscopy of cryogenically cooled gas phase host-guest complex ions of crown ethers $\uparrow$}

\author{
Yoshiya Inokuchi, ${ }^{a}$ Takeharu Haino, ${ }^{a}$ Ryo Sekiya, ${ }^{a}$ Fumiya Morishima, ${ }^{a}$ \\ Claude Dedonder, ${ }^{\mathrm{b}}$ Géraldine Féraud, ${ }^{\mathrm{b}}$ Christophe Jouvet ${ }^{\star \mathrm{b}}$ and Takayuki Ebata*a
}

\begin{abstract}
The geometric and electronic structures of cold host-guest complex ions of crown ethers (CEs) in the gas phase have been investigated by ultraviolet (UV) fragmentation spectroscopy. As host CEs, we chose 15-crown-5 (15C5), 18-crown-6 (18C6), 24-crown-8 (24C8), and dibenzo-24-crown-8 (DB24C8), and as guests protonated-aniline (aniline $\cdot \mathrm{H}^{+}$) and protonated-dibenzylamine $\left(\mathrm{dBAM} \cdot \mathrm{H}^{+}\right)$were chosen. The ions generated by an electrospray ionization (ESI) source were cooled in a quadrupole ion-trap (QIT) using a cryogenic cooler, and UV spectra were obtained by UV photodissociation (UVPD) spectroscopy. UV spectroscopy was complemented by quantum chemical calculations of the most probable complex structures. The UV spectrum of aniline $\cdot \mathrm{H}^{+}$. CEs is very sensitive to the symmetry of CEs; aniline $\cdot \mathrm{H}^{+} \cdot 18 \mathrm{C} 6$ shows a sharp electronic spectrum similar to aniline $\cdot \mathrm{H}^{+}$, while aniline $\cdot \mathrm{H}^{+} \cdot 15 \mathrm{C} 5$ shows a very broad structure with poor FranckCondon factors. In addition, a remarkable cage effect in the fragmentation process after UV excitation was observed in both complex ions. In aniline $\cdot \mathrm{H}^{+}$. CE complexes, the cage effect completely removed the dissociation channels of the aniline $\mathrm{H}^{+}$moiety. A large difference in the fragmentation yield between $\mathrm{dBAM} \cdot \mathrm{H}^{+} \cdot 18 \mathrm{C} 6$ and $\mathrm{dBAM} \cdot \mathrm{H}^{+} \cdot 24 \mathrm{C} 8$ was observed due to a large barrier for releasing $\mathrm{dBAM} \cdot \mathrm{H}^{+}$from the axis of rotaxane in the latter complex.
\end{abstract}

\section{Introduction}

Crown ethers (CEs) are macrocyclic ethers built with oxyethylene $\left(-\mathrm{CH}_{2}-\mathrm{CH}_{2}-\mathrm{O}-\right)$ units. Pedersen synthesized the first crown ether (CE) dibenzo-18-crown-6 (DB18C6), in 1967 and investigated complexation with various metal salts ${ }^{1,2}$ using UV spectroscopy. Since then, CEs have been playing an important role in hostguest and supramolecular chemistry. CEs can include not only metal ions in their cavity but also form various complexes with ionic and neutral species through non-covalent interactions. Applications of CEs as molecular receptors, metal cation extraction agents, fluoroionophores and phase transfer catalytic media have been described in a number of studies. ${ }^{3-14}$ Especially, it is well known that, in the condensed phase, CEs exhibit selectivity when they include the guest species. ${ }^{9-14}$ This selectivity is described by the matching between the size of the guest species and that of the CE cavity. On the other hand, the host-guest

\footnotetext{
${ }^{a}$ Department of Chemistry, Graduate School of Science, Hiroshima University, Higashi-Hiroshima 739-8526, Japan.E-mail: tebata@hiroshima-u.ac.jp

${ }^{b}$ CNRS, Aix Marseille Université, Physique des Interactions Ioniques et Moléculaires (PIIM) UMR 7345, 13397 Marseille Cedex, France.

E-mail: christophe.jouvet@univ-amu.fr

$\dagger$ Electronic supplementary information (ESI) available. See DOI: 10.1039/c5cp01960e
}

binding energy measured in the gas phase shows different characteristics from those observed in the condensed phase. ${ }^{15-17}$ This discrepancy requires the search for more information on the intrinsic nature of CEs, such as the flexibility of the CE frame and conformation preference, as well as solvent effects on the stability of the inclusion complexes.

To investigate the difference between condensed phase and gas phase studies and to obtain information on the host-guest interaction at the microscopic level, we have been studying the structures, conformation preference, and selectivity of guests for the inclusion complexes of CEs in the gas phase. ${ }^{18-27}$ The cold gas phase complexes are generated either by the supersonic expansion technique for neutral complexes ${ }^{18-24}$ or by the electrospray ionization (ESI)/cold ion-trap method for ionic complexes. ${ }^{24-27} \mathrm{We}$ apply various laser spectroscopic methods to record conformer specific UV and IR spectra, and the spectra are analyzed by comparing with the spectra of possible complexes obtained by quantum chemical calculations. Based on these studies, we reported that the conformations of CEs in the inclusion complexes are generally different from the most stable conformer of bare forms, because CEs will change their structures so that they can include the different size and structure of guest species in their cavities. ${ }^{20,22,23}$

In the present work, we report a study on host-guest complexes of CEs with protonated aromatic amines. CEs can be good 
receptors of protonated amines since stable complexes can be formed via multiple $\mathrm{NH}$. .O hydrogen bonds. First, we investigate the inclusion complexes of protonated aniline (aniline $\cdot \mathrm{H}^{+}$) with 18-crown-6 (18C6) and 15-crown-5 (15C5). These complexes have a structure in which the $\mathrm{NH}_{3}{ }^{+}$group of aniline $\cdot \mathrm{H}^{+}$(guest) is bonded to $18 \mathrm{C} 6$ or $15 \mathrm{C} 5$ (host) through $\mathrm{N}-\mathrm{H} \cdots \mathrm{O}$ hydrogen bonds. In a previous study, we reported that UV photodissociation (UVPD) of aniline $\cdot \mathrm{H}^{+}$generates aniline ${ }^{+}$and $\mathrm{C}_{6} \mathrm{H}_{5}{ }^{+}$fragment ions. ${ }^{28}$ Here we examine how the complex formation affects the electronic spectrum of aniline $\cdot \mathrm{H}^{+}$as well as the UVPD pattern. Second, we report the host-guest complexes between protonated dibenzylamine (dBAM $\left.\cdot \mathrm{H}^{+}\right)$with 18C6, 24-crown-8 (24C8), and dibenzo-24-crown-8 (DB24C8). dBAM $\cdot \mathrm{H}^{+}$is used as an axis molecule of rotaxane. Rotaxane molecules have attracted great interest due to their potential use in molecular machines, such as molecular switches ${ }^{29-33}$ and molecular shuttles. ${ }^{34-36}$ In this study, we recorded the UV electronic spectra and the fragmentation yield after UV excitation of the complexes between dBAM $\cdot \mathrm{H}^{+}$ and 18C6, 24C8 and DB24C8. We investigate how the complex or rotaxane formation changes the electronic structure of constituent chromophores and the UVPD pattern by comparing the observed spectra with those of the possible structures obtained by quantum chemical calculations.

\section{Experimental and computational}

\section{Experimental setup}

The experimental setup has been described in previous papers. ${ }^{28,37,38}$ The setup consists of three parts: an ESI source, a cryogenically cooled quadrupole-ion-trap (QIT) and a time-offlight mass spectrometer (TOF-Mass). ${ }^{39,40}$ Protonated ions are produced in the ESI source ${ }^{41}$ and trapped in an octopole trap at the exit of the capillary. They are extracted by a negative electric pulse and are further accelerated by a second electric pulse just after the exit electrode. The ions are driven by a couple of electrostatic lenses toward the Paul trap. A mass gate at the entrance of the trap selects the parent ion. The ions are trapped in the Paul trap cooled using a cryostat (Coolpak Oerlikon) and filled with helium buffer gas injected using a pulsed valve. The ions are thermalized at around $30 \mathrm{~K}$ while they stay in the trap. After $60 \mathrm{~ms}$, the UV laser is introduced to dissociate the cold ions, and after another $30 \mathrm{~ms}$ the fragments and remaining parent ions are extracted using a TOF spectrometer and are detected using a microchannel plate (MCP) detector. The UV spectrum is obtained by scanning the laser frequency and recording the ion fragments using a MCP detector. We use an OPO laser (EKSPLA model-NT342B) as the UV light source, and its spectral resolution is $8 \mathrm{~cm}^{-1}$. The unfocused laser is shaped to a $2 \mathrm{~mm}^{2}$ spot in the trap, corresponding to a power of $c a .5 \mathrm{~mW}$.

\section{Computational}

For the structural calculation of $\mathrm{dBAM} \cdot \mathrm{H}^{+}$, and complexes of aniline $\cdot \mathrm{H}^{+}$and dBAM $\cdot \mathrm{H}^{+}$with crown ethers, possible conformers were first searched by selecting some initial geometries optimized at the AM1 level, ${ }^{42}$ and the obtained structures were optimized by density functional theory calculations using M05-2X/6-31+G*.

To obtain plausible structures of DB24C8 $\cdot \mathrm{H}^{+}$and $\mathrm{dBAM} \cdot \mathrm{H}^{+}$. DB24C8 complexes, we first used a classical force field to search initial conformations. We performed a Monte Carlo simulation by a mixed torsional search with low-mode sampling using MacroModel ${ }^{43}$ V.9.1 with a MMFF94s force field, ${ }^{44}$ and optimized the geometries using the Polak-Ribiere conjugate gradient (PRCG) algorithm ${ }^{45}$ with a convergence threshold of $0.05 \mathrm{~kJ} \mathrm{~mol}^{-1}$. From this calculation, 10 isomers for the DB24C8 $\cdot \mathrm{H}^{+}$complex and 3 isomers for $\mathrm{dBAM} \cdot \mathrm{H}^{+} \cdot \mathrm{DB} 24 \mathrm{C} 8$ were obtained within $10 \mathrm{~kJ} \mathrm{~mol}^{-1}$ of the most stable one. All these isomers were geometry-optimized by DFT calculations at the M05-2X/6-31+G* level with loose optimization criteria. Quantum chemical calculations were performed using the Gaussian 09 program package. $^{46}$

\section{Synthesis of materials}

Dibenzylammonium hexafluorophosphate $\left(\mathrm{dBAM} \cdot \mathrm{H}^{+} \cdot \mathrm{PF}_{6}{ }^{-}\right)$: $\mathrm{dBAM} \cdot \mathrm{H}^{+} \cdot \mathrm{PF}_{6}{ }^{-}$was synthesized by a procedure previously reported by Ashton et al. ${ }^{47}$ Aqueous hydrogen chloride $\left(1 \mathrm{~mol} \mathrm{~L}^{-1}, 26.1 \mathrm{~mL}\right)$ was added to dibenzylamine $(26.1 \mathrm{mmol})$, and the solution was stirred for $1.5 \mathrm{~h}$ at room temperature. The solvent was removed under vacuum and the residue was dissolved in hot deionized water $\left(100 \mathrm{~mL}, 70{ }^{\circ} \mathrm{C}\right)$. Saturated aqueous ammonium hexafluorophosphate was added until no further precipitation occurred. The white solid was filtered off and dried to afford $8.34 \mathrm{~g}$ of the desired product $(93 \%)$.

Pseudo-rotaxanes: $\mathrm{dBAM} \cdot \mathrm{H}^{+} \cdot \mathrm{DB} 24 \cdot \mathrm{PF}_{6}{ }^{-}$was prepared from DB24C8 and dBAM $\cdot \mathrm{H}^{+} \cdot \mathrm{PF}_{6}{ }^{-} \cdot \mathrm{DB} 24 \mathrm{C} 8(100 \mathrm{mg}, 0.222 \mathrm{mmol}$ ) was dissolved in chloroform $(10 \mathrm{~mL})$, and then $\mathrm{dBAM} \cdot \mathrm{H}^{+} \cdot \mathrm{PF}_{6}{ }^{-}$ salt $(76.6 \mathrm{mg}, 0.223 \mathrm{mmol})$ was added. After being stirred for $1 \mathrm{~h}$ at room temperature, the mixture was concentrated in vacuo to afford $167 \mathrm{mg}$ of the pseudo-rotaxane (94\%) as a white solid.

$\mathrm{dBAM} \cdot \mathrm{H}^{+} \cdot 24 \mathrm{C} 8 \cdot \mathrm{PF}_{6}{ }^{-}$was prepared from $24 \mathrm{C} 8$ and $\mathrm{dBAM} \cdot \mathrm{H}^{+}$. $\mathrm{PF}_{6}{ }^{-}$. 24C8 (72.0 mg, $0.204 \mathrm{mmol}$ ) was dissolved in chloroform $(5 \mathrm{~mL})$, and then dBAM $\cdot \mathrm{H}^{+} \cdot \mathrm{PF}_{6}{ }^{-}$salt $(70.1 \mathrm{mg}, 0.204 \mathrm{mmol})$ was added. After being stirred for $0.5 \mathrm{~h}$ at room temperature, the mixture was concentrated in vacuo to afford $132 \mathrm{mg}$ of the pseudo-rotaxane (93\%) as a white solid.

The rotaxane formation was confirmed using $\mathrm{dBAM} \cdot \mathrm{H}^{+}$ NMR spectroscopy. The catechol protons split two resonances, one of which was slightly upfield-shifted. Two sets of the oxymethylene protons of DB24C8 showed the up-field shifts of 0.16 and $0.05 \mathrm{ppm}$, respectively. Two benzene rings of bound $\mathrm{dBAM} \cdot \mathrm{H}^{+} \cdot \mathrm{PF}_{6}{ }^{-}$face one another as found in the crystal structure. The crown moiety is placed within the cleft of the benzene rings; therefore, aromatic shielding most likely resulted in the up-field shifts of the crown protons. A similar chemical shift change was observed in the ${ }^{1} \mathrm{H}$ NMR spectrum of dBAM. $\mathrm{H}^{+} \cdot 24 \mathrm{C} 8 \cdot \mathrm{PF}_{6}{ }^{-}$. The oxyethylene protons of $24 \mathrm{C} 8$ showed an up-field shift of $0.19 \mathrm{ppm}$. These sets of evidence are consistent with those reported by Ashton et al. ${ }^{47}$ 


\section{Results and discussion}

\section{Protonated aniline crown ether complex ions}

The left panel of Fig. 1 shows the UVPD spectra of (a) aniline. $\mathrm{H}^{+}$, (b) aniline $\cdot \mathrm{H}^{+} \cdot 18 \mathrm{C} 6$, and (c) aniline $\cdot \mathrm{H}^{+} \cdot 15 \mathrm{C} 5$ ions in the $35000-44000 \mathrm{~cm}^{-1}$ region. The excess proton in aniline $\mathrm{H}^{+}$is attached to the amino group, forming the anilinium ion, $\mathrm{C}_{6} \mathrm{H}_{5} \mathrm{NH}_{3}{ }^{+}$. The right panel of Fig. 1 shows the time of flight (TOF) spectra of aniline $\cdot \mathrm{H}^{+}$without (blue) and with UV (red) laser irradiation. As shown in the figure, the main photofragment ions for aniline $\cdot \mathrm{H}^{+}$ are aniline ${ }^{+}(\mathrm{m} / \mathrm{z}=93)$ and $\mathrm{C}_{6} \mathrm{H}_{5}{ }^{+}(\mathrm{m} / \mathrm{z}=77)$, produced by $\mathrm{H}$ atom loss or $\mathrm{NH}_{3}$ loss, respectively. ${ }^{45}$ The UVPD spectrum of the aniline $\cdot \mathrm{H}^{+}$ion shows a band origin at $38215 \mathrm{~cm}^{-1}$, which is $\sim 4200 \mathrm{~cm}^{-1}$ blue-shifted as compared to the transition origin of neutral aniline $\left(34027 \mathrm{~cm}^{-1}\right){ }^{48}$ This blue shift between the transitions of ionic and neutral species is the largest observed for the systems investigated here. It can be assigned to the deconjugation of the nitrogen lone pair when $\mathrm{H}^{+}$attaches to the amino group so that aniline $\cdot \mathrm{H}^{+}$has a toluene like electronic structure (the $(0,0)$ band of the toluene $\mathrm{S}_{1}-\mathrm{S}_{0}$ transition is located at $\left.37477 \mathrm{~cm}^{-1}\right){ }^{46,49}$ A progression in a mode of $\sim 920 \mathrm{~cm}^{-1}$ can be followed by starting from the band origin, as shown with solid lines in Fig. 1a, which is assigned to the ring breathing mode (mode 1). ${ }^{50}$ This frequency is closer to that of neutral toluene $\left(935 \mathrm{~cm}^{-1}\right)$ than that of aniline $\left(952 \mathrm{~cm}^{-1}\right)$.

In the case of the aniline $\cdot \mathrm{H}^{+} \cdot 18 \mathrm{C} 6$ complex, two sharp bands are observed at 38565 and $38640 \mathrm{~cm}^{-1}$ (Fig. 1b). Since one cannot see any strong band or progression around these two bands, they may probably be ascribed to the origin band of two different isomers. The position of the origin bands is much closer to that of aniline $\cdot \mathrm{H}^{+}$than to that of neutral aniline, thus the proton is still located on the amino group of the aniline part. The UVPD spectrum of aniline $\cdot \mathrm{H}^{+} \cdot 18 \mathrm{C} 6$ also shows a progression with an interval of $\sim 920 \mathrm{~cm}^{-1}$ similar to aniline $\cdot \mathrm{H}^{+}$as highlighted by solid lines in Fig. 1b, although the transitions to higher vibrational levels show broadened features. Since the frequency of the ring breathing mode is almost the same for aniline $\cdot \mathrm{H}^{+}$and aniline $\cdot \mathrm{H}^{+} \cdot 18 \mathrm{C} 6$ ions, the benzene ring in the aniline $\cdot \mathrm{H}^{+} \cdot 18 \mathrm{C} 6$ ion seems not to be strongly affected by the $18 \mathrm{C} 6$ part. The right panel of Fig. 1 shows the TOF spectra of aniline $\cdot \mathrm{H}^{+} \cdot 18 \mathrm{C} 6$. We find that the fragment pattern is quite different from that of aniline $\cdot \mathrm{H}^{+}$. Three photofragment ions are observed for aniline $\cdot \mathrm{H}^{+} \cdot 18 \mathrm{C} 6 ; 18 \mathrm{C} 6 \cdot \mathrm{H}^{+}(\mathrm{m} / z=265),\left(\mathrm{OCH}_{2} \mathrm{CH}_{2}\right)_{4} \cdot \mathrm{H}^{+}(\mathrm{m} / \mathrm{z}=$ $177)$, and $\left(\mathrm{OCH}_{2} \mathrm{CH}_{2}\right)_{3} \cdot \mathrm{H}^{+}(m / z=133)$; no fragment ion due to the dissociation of the aniline $\cdot \mathrm{H}^{+}$part, $\mathrm{H}$ loss (dissociation of an $\mathrm{NH}$ bond) or $\mathrm{NH}_{3}$ loss (dissociation of the $\mathrm{CN}$ bond), is observed. The $\mathrm{CN}$ bond breaking observed in the UVPD of aniline $\cdot \mathrm{H}^{+}$could lead to the formation of the $\mathrm{CE} \cdot \mathrm{NH}_{3}{ }^{+}$fragment, but is not observed either. The fragmentation pattern rather indicates that a proton transfer occurs from aniline $\cdot \mathrm{H}^{+}$to 18C6 after the UV excitation, and the excess energy initially injected in the aniline $\cdot \mathrm{H}^{+}$part efficiently flows to the $18 \mathrm{C} 6$ part. After UV excitation, the aniline $\cdot \mathrm{H}^{+} \cdot 18 \mathrm{C} 6$ complex may relax to the ground state and transfer a proton and energy to the 18C6 part, leading to fragmentation in aniline and $18 \mathrm{C} 6 \cdot \mathrm{H}^{+} \cdot 18 \mathrm{C} 6 \cdot \mathrm{H}^{+}$has enough internal energy to further fragment into $\left(\mathrm{OCH}_{2} \mathrm{CH}_{2}\right)_{4} \cdot \mathrm{H}^{+}$ or $\left(\mathrm{OCH}_{2} \mathrm{CH}_{2}\right)_{3} \cdot \mathrm{H}^{+}$as observed. Thus, $18 \mathrm{C} 6$ has a role of a reservoir of energy; the energy initially imparted by the optical excitation into electronic and vibrational energy of the aniline part is transferred to 18C6, a kind of cage effect. As shown in Fig. S1 in
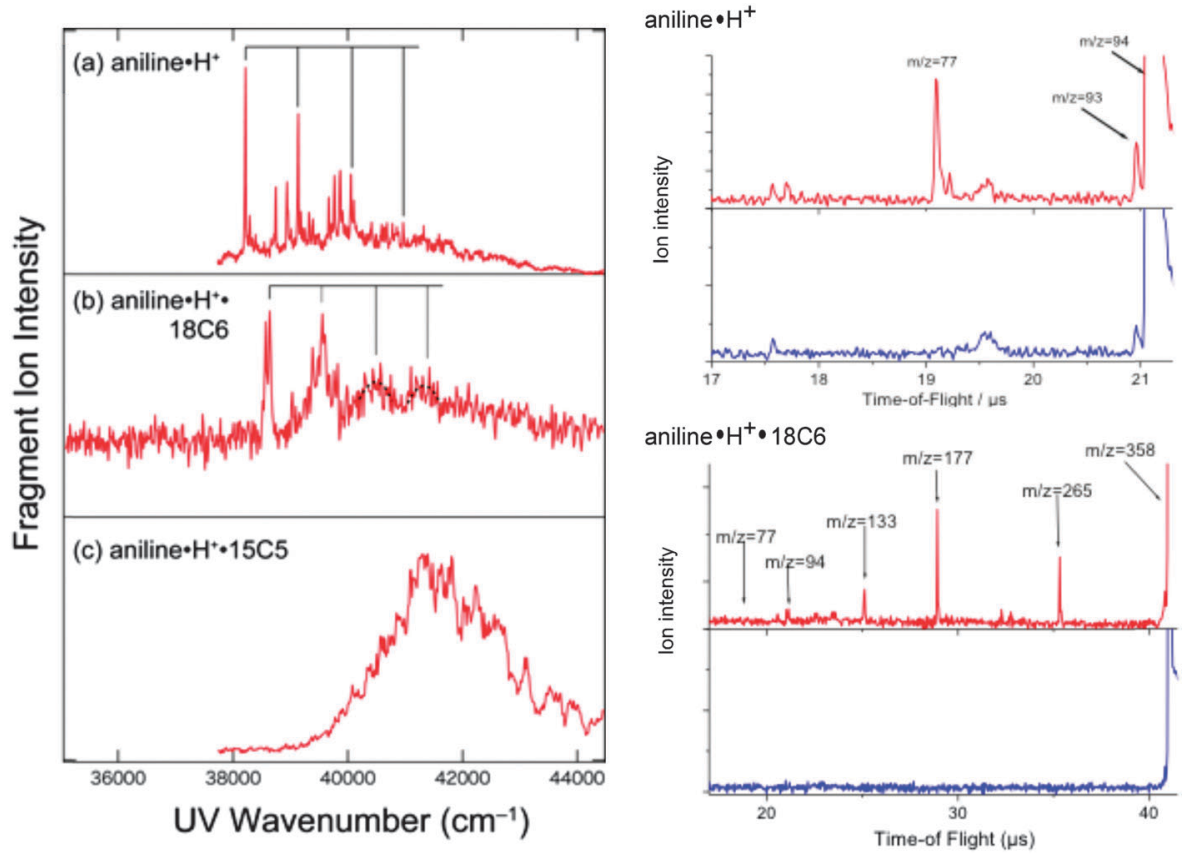

Fig. 1 (left) UVPD spectra of (a) aniline $\cdot \mathrm{H}^{+}$, (b) aniline $\cdot \mathrm{H}^{+} \cdot 18 \mathrm{C} 6$, and (c) aniline $\cdot \mathrm{H}^{+} \cdot 15 \mathrm{C} 5$. (right) TOF spectra of aniline $\cdot \mathrm{H}^{+}$and aniline $\cdot \mathrm{H}^{+} \cdot 18 \mathrm{C} 6$, without UV irradiation (blue) and with UV irradiation fixed at the band origins (red). The solid black lines in (a) and (b) show the progression with an interval of $\sim 920 \mathrm{~cm}^{-1}$ assigned to the ring breathing mode. 
the ESI, $\dagger$ the intensity of the $\left(\mathrm{OCH}_{2} \mathrm{CH}_{2}\right)_{4} \cdot \mathrm{H}^{+}$fragment ion becomes stronger than that of $18 \mathrm{C} 6 \cdot \mathrm{H}^{+}$with increasing UV photon energy; the formation of $\left(\mathrm{OCH}_{2} \mathrm{CH}_{2}\right)_{4} \cdot \mathrm{H}^{+}$requires more energy than that of $18 \mathrm{C} 6 \cdot \mathrm{H}^{+}$and the fragmentation occurs statistically after the proton and energy transfer from aniline $\cdot \mathrm{H}^{+}$to $18 \mathrm{C} 6$.

In contrast to aniline $\cdot \mathrm{H}^{+}$and aniline $\cdot \mathrm{H}^{+} \cdot 18 \mathrm{C} 6$, the UVPD spectrum of aniline $\cdot \mathrm{H}^{+} \cdot 15 \mathrm{C} 5$ (Fig. 1c) shows a broad absorption in the region of $39000-44000 \mathrm{~cm}^{-1}$. In aniline $\cdot \mathrm{H}^{+} \cdot 15 \mathrm{C} 5$, the proton is attached to the $\mathrm{NH}_{2}$ group of the aniline part as in aniline $\cdot \mathrm{H}^{+} \cdot 18 \mathrm{C} 6$. However, the UV spectrum of the aniline $\cdot \mathrm{H}^{+}$. $15 \mathrm{C} 5$ ion is quite different from that of aniline $\cdot \mathrm{H}^{+} \cdot 18 \mathrm{C} 6$, which may imply a poor Franck-Condon overlap between the $\mathrm{S}_{0}$ and $S_{1}$ states.

Fig. 2 shows the typical structures of (a) aniline $\cdot \mathrm{H}^{+} \cdot 18 \mathrm{C} 6$ and (b) aniline $\cdot \mathrm{H}^{+} \cdot 15 \mathrm{C} 5$ complexes. In the aniline $\cdot \mathrm{H}^{+} \cdot 18 \mathrm{C} 6$ complex, the $\mathrm{NH}_{3}{ }^{+}$group is bonded to $18 \mathrm{C} 6$ through three $\mathrm{N}-\mathrm{H} \cdots \mathrm{O}$ hydrogen bonds as was expected. This intermolecular bond seems to result in effective proton transfer from aniline $\cdot \mathrm{H}^{+}$to $18 \mathrm{C} 6$ after the UV excitation. The $\mathrm{H} \cdots \mathrm{O}$ distances are almost the same ( $\sim 1.83 \AA$ ) for all the three hydrogen bonds; the 18C6 cavity seems to be well fitted to the $\mathrm{NH}_{3}{ }^{+}$group. The $18 \mathrm{C} 6$ component and the aromatic ring are located apart, so that there is no strong intermolecular interaction between 18C6 and the benzene ring, which is consistent with the similar frequency observed in the UVPD spectra of aniline $\cdot \mathrm{H}^{+}$and aniline $\cdot \mathrm{H}^{+} \cdot 18 \mathrm{C} 6$ ions for the benzene breathing-mode. The proton transfer from aniline $\cdot \mathrm{H}^{+}$

(a) Aniline $\bullet \mathrm{H}^{+} \cdot 18 \mathrm{C} 6$

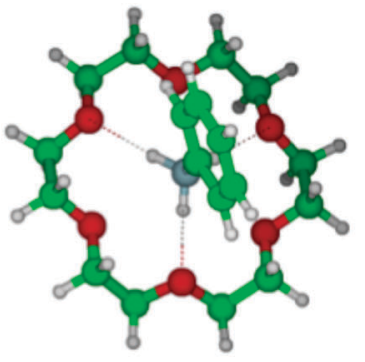

Top View

(b) Aniline $\cdot \mathrm{H}^{+} \cdot 15 \mathrm{C5}$

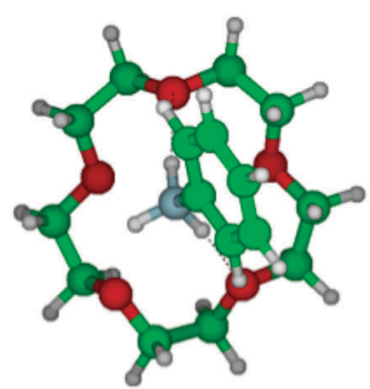

Top View

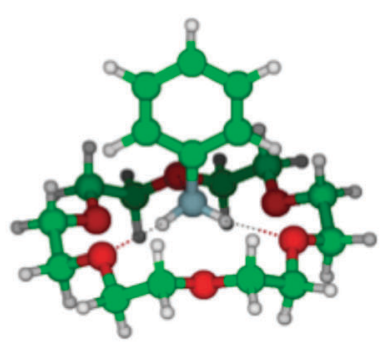

Side View

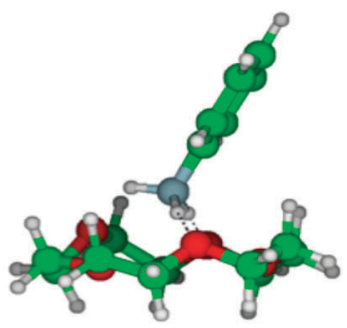

Side View
Fig. 2 Typical stable geometries of (a) aniline $\cdot \mathrm{H}^{+} \cdot 18 \mathrm{C} 6$ and (b) aniline $\cdot \mathrm{H}^{+} \cdot 15 \mathrm{C} 5$. to $18 \mathrm{C} 6$ after UV excitation of the complex is understood in terms of larger proton affinity (PA) of the crown ether $\left(967.0 \mathrm{~kJ} \mathrm{~mol}^{-1}\right)$ than that of aniline $\left(882.5 \mathrm{~kJ} \mathrm{~mol}^{-1}\right) .{ }^{51}$ After UV excitation, the proton transfer occurs from aniline $\cdot \mathrm{H}^{+}$to $18 \mathrm{C} 6$ in the $\mathrm{S}_{1}$ excited state of the complex or after the relaxation to $S_{0}$ by internal conversion (IC).

For the aniline $\cdot \mathrm{H}^{+} \cdot 15 \mathrm{C} 5$ complex, the proton is also initially situated on the aniline molecule, and the aniline $\cdot \mathrm{H}^{+}$ion is bonded to $15 \mathrm{C} 5$ through two $\mathrm{N}-\mathrm{H}$. . O hydrogen bonds, instead of three $\mathrm{H}$-bonds in aniline $\cdot \mathrm{H}^{+} \cdot 18 \mathrm{C} 6$. The PA of $15 \mathrm{C} 5$ is $943.8 \mathrm{~kJ} \mathrm{~mol}{ }^{-1}, 48$ larger than that of aniline; thus, after UV excitation, the proton of aniline $\cdot \mathrm{H}^{+}$is also transferred to 15C5. The difference in the UV spectral patterns between the aniline $\cdot \mathrm{H}^{+} \cdot 18 \mathrm{C} 6$ and aniline $\cdot \mathrm{H}^{+} \cdot 15 \mathrm{C} 5$ ions can be assigned to the asymmetry of the hydrogen bond network in the aniline $\cdot \mathrm{H}^{+} \cdot 15 \mathrm{C} 5$ ion that distorts the structure of the complex and leads to a change in geometry between the ground and excited states, which results in a poor Franck-Condon overlap in the UVPD spectrum (Fig. 1c). Another possibility to explain the broad feature of the UV spectrum of aniline $\cdot \mathrm{H}^{+} \cdot 15 \mathrm{C} 5$ is the coexistence of other isomer(s) in aniline. $\mathrm{H}^{+}$.15C5. Pasker et al. investigated aniline $\cdot \mathrm{H}^{+}$and its complexes by infrared photo-dissociation (IRPD) spectroscopy and theoretical calculations, ${ }^{52}$ and reported that aniline $\cdot \mathrm{H}^{+}$has two almost equally stable isomers, the ammonium and carbenium isomers, and that their relative population changes with complexation. It may be possible that the asymmetrical hydrogen-bonding of the aniline $\cdot \mathrm{H}^{+} \cdot 15 \mathrm{C} 5$ complex induces a larger population of the carbenium isomers, which should have different vibronic structures than the ammonium type isomer. However, calculations show that the ground state carbenium complex with 15C5 is more than $1 \mathrm{eV}$ higher in energy than the anilinium-15C5 complex, because in the carbenium ion the positive charge is largely delocalized whereas in the ammonium ion the charge is well localized on the ammonium group.

The UV excitation does not produce any fragment ion via the loss of $\mathrm{H}$ atom or $\mathrm{NH}_{3}$ loss neither in aniline $\cdot \mathrm{H}^{+} \cdot 18 \mathrm{C} 6$ nor in aniline $\cdot \mathrm{H}^{+} \cdot 15 \mathrm{C} 5$, which differs from the UVPD of bare aniline $\cdot \mathrm{H}^{+}$. The crown ether induced cage effect on the fragmentation of anilinium is surprising. While it is easy to understand that the cage will suppress the $\mathrm{H}$ loss channel from anilinium, the absence of the $\mathrm{NH}_{3}$ loss channel, which is one of the major fragments in the anilinium ion, is unexpected. This is in contrast to the protonated tryptamine case in which the $\mathrm{C}-\mathrm{NH}_{3}$ bond breaking is observed both in the free ion $^{53}$ and in the complex with $18 C 6 .{ }^{54}$ In the complex, this fragmentation channel was assigned to an excited state dissociation, which thus seems to be absent in anilinium. CE complexes.

\section{Protonated dibenzylamine $\left(\mathbf{d B A M} \cdot \mathbf{H}^{+}\right)$}

Protonated dibenzylamine $\left(\mathrm{dBAM} \cdot \mathrm{H}^{+}\right)$is used as an axis molecule in pseudo-rotaxane. We investigate how the rotaxane formation affects the electronic transition of $\mathrm{dBAM} \cdot \mathrm{H}^{+}$. Fig. 3 shows the UVPD spectrum of dBAM $\cdot \mathrm{H}^{+}$obtained by monitoring the $m / z=107\left(\mathrm{C}_{7} \mathrm{NH}_{9}{ }^{+}\right)$major fragment. The spectrum is essentially the same as that reported in our previous paper, ${ }^{38}$ except the spectrum is recorded in a wider energy region. A sharp $(0,0)$ 


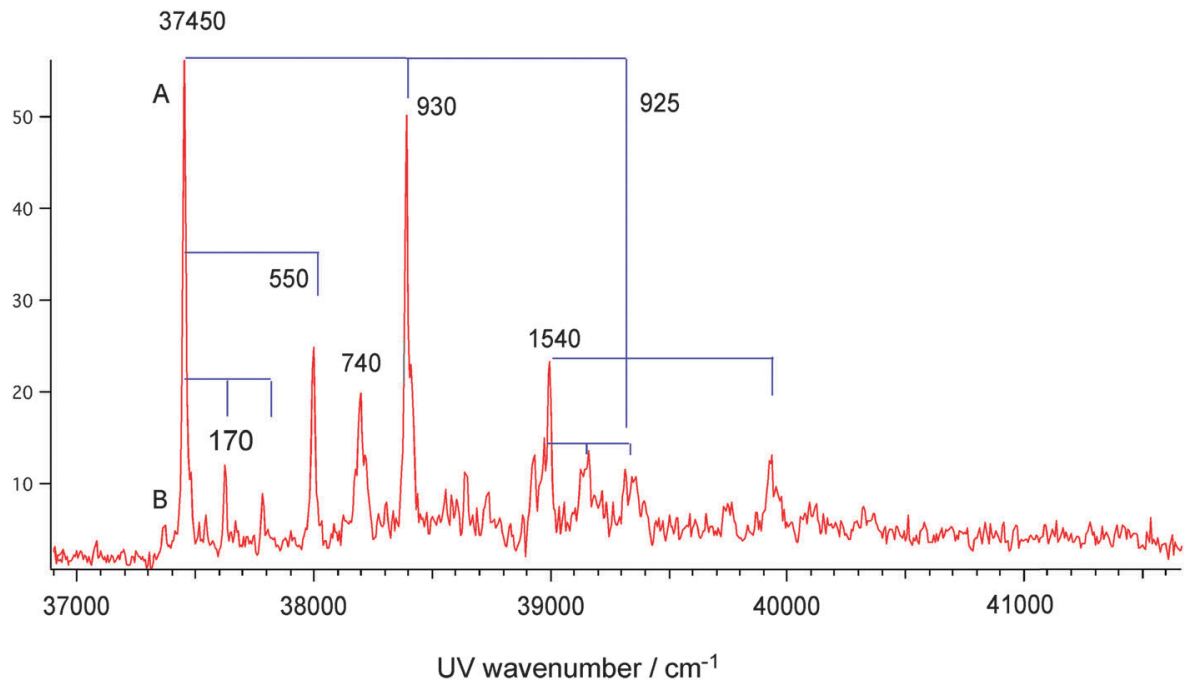

Fig. 3 UVPD spectrum of cold protonated dibenzylamine $\left(\mathrm{dBAM} \cdot \mathrm{H}^{+}\right)$in the gas phase.

band appears at $37450 \mathrm{~cm}^{-1}$ (band A) along with several sharp vibronic bands involving torsional mode $\left(170 \mathrm{~cm}^{-1}\right)$ and skeletal modes $\left(550,745,930\right.$ and $\left.1540 \mathrm{~cm}^{-1}\right)$. The vibronic structure corresponding to skeletal modes is very similar to that of aniline $\cdot \mathrm{H}^{+}$. Additionally, a weak band (band $\mathrm{B}$ ) is observed at $70 \mathrm{~cm}^{-1}$ on the lower frequency side of band A. We investigated the temperature dependence of bands $\mathrm{A}$ and $\mathrm{B}$, and found that the relative intensity of band $\mathrm{B}$ with respect to band $\mathrm{A}$ increases with the increase of the temperature of the trap (see ESI, $\dagger$ Fig. S2). Thus it is found that band B is due to either a hot band or a higher energy conformer.

Possible structures of dBAM $\cdot \mathrm{H}^{+}$have been investigated by DFT calculations at the M05-2X/6-31+G* level. Three stable conformers were obtained: (1) an open conformer, (2) a twisted conformer, and (3) a stacked conformer as shown in Fig. 4. Table 1 shows their relative ground state and vertical excitation energies. Conformers (1) and (2) have very similar ground state energies; conformer (2) being $4.3 \mathrm{~kJ} \mathrm{~mol}^{-1}$ higher than conformer (1) without zero point energy (ZPE) correction. Conformer (3) has a higher energy $\left(85.4 \mathrm{~kJ} \mathrm{~mol}^{-1}\right)$, and is not expected to be present in the trap. Since $\mathrm{dBAM} \cdot \mathrm{H}^{+}$has two benzene chromophores, we expect two closely lying electronic states, $\mathrm{S}_{1}$ and $S_{2}$, corresponding to the excitation of each of the two chromophores. In the UVPD spectrum, strong band A and weak band B are observed. Since they show different temperature dependencies, band A can be assigned to the most stable open conformer and band B to the twisted conformer. Table 1 also lists the vertical excitation energies to $S_{1}$ and $S_{2}$ states and their oscillator strengths calculated by TD-DFT calculations at the M05-2X/6-31+G* level. As shown in Table $1, S_{1}$ and $S_{2}$ states are located at almost the same energy for the open and twisted conformers, and the oscillator strength of the $\mathrm{S}_{1}-\mathrm{S}_{0}$ transition of the open conformer is zero, which is due to the cancelation of the transition dipoles of the two constituent benzene chromophores. The calculated results are in accordance with the observation of a single band origin, band A, in the UVPD spectrum corresponding to the open conformer, and weak band $\mathrm{B}$ corresponding to the twisted conformer.

\section{Complexes of dBAM $\cdot \mathrm{H}^{+}$with $18 \mathrm{C6}$ and $24 \mathrm{C} 8$}

dBAM $\cdot \mathrm{H}^{+}$does not go through the $18 \mathrm{C} 6$ ring due to steric hindrance, but dBAM $\cdot \mathrm{H}^{+}$can go through the $24 \mathrm{C} 8$ ring to form

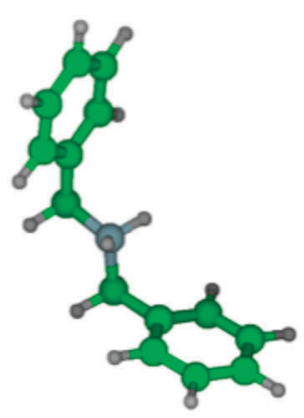

(1) Open conformer

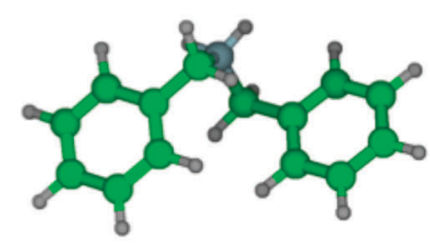

(2) Twisted conformer

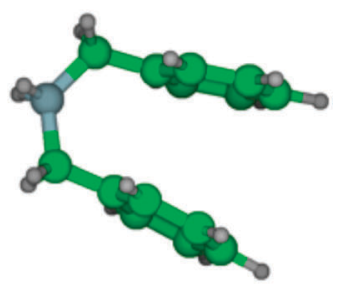

(3) Stacked conformer

Fig. 4 Optimized structures of $\mathrm{dBAM} \cdot \mathrm{H}^{+}$conformers at the $\mathrm{M} 05-2 \mathrm{X} / 6-31+\mathrm{G}^{*}$ level. 
Table 1 Relative ground state stabilization energies $\left(\mathrm{kJ} \mathrm{mol}^{-1}\right)$, vertical excitation energies (eV) and oscillator strength (parentheses) for the three $\mathrm{dBAM} \cdot \mathrm{H}^{+}$conformers calculated at the M05-2X/6-31+G*level

\begin{tabular}{llll}
\hline Conformer & Open & Twisted & Stacked \\
\hline $\left.\mathrm{S}_{0}(\mathrm{~kJ} \mathrm{~mol})^{-1}\right)$ & 0 & 4.3 & 85.4 \\
$\mathrm{~S}_{1}(\mathrm{eV})$ & $5.57(0.0)$ & $5.56\left(2.0 \times 10^{-4}\right)$ & $4.93(0.0)$ \\
$\mathrm{S}_{2}(\mathrm{eV})$ & $5.58\left(9.8 \times 10^{-3}\right)$ & $5.57\left(8.1 \times 10^{-3}\right)$ & $5.12\left(3.9 \times 10^{-2}\right)$
\end{tabular}

a pseudo-rotaxane. ${ }^{47}$ So, we investigated how the difference in complex structure will be reflected in the UV spectra and fragmentation yields of the two complexes.

Fig. $5 \mathrm{~b}$ and $\mathrm{c}$ show the UVPD spectra of dBAM $\cdot \mathrm{H}^{+} \cdot 18 \mathrm{C} 6$ and dBAM $\cdot \mathrm{H}^{+} \cdot 24 \mathrm{C} 8$ complex ions. At the opposite of the aniline $\cdot \mathrm{H}^{+}$. 18C6 UVPD, we observed dBAM $\cdot \mathrm{H}^{+}$fragment ions $(\mathrm{m} / \mathrm{z}=198)$ instead of CE. $\mathrm{H}^{+}$in both cases (see the TOF spectra in the right panels of Fig. 5), and the UVPD spectra are recorded by monitoring the dBAM $\cdot \mathrm{H}^{+}$fragment in both cases. The PA value of dBAM is not known, but that of benzylamine is reported to be $913 \mathrm{~kJ} \mathrm{~mol}^{-1}$. Since we do not observe the $18 \mathrm{C} 6 \cdot \mathrm{H}^{+}$fragment, the PA of dBAM should be larger than that of $18 \mathrm{C} 6\left(967 \mathrm{~kJ} \mathrm{~mol}^{-1}\right)$. The UVPD spectra of dBAM $\cdot \mathrm{H}^{+} \cdot 18 \mathrm{C} 6$ and $\mathrm{dBAM} \cdot \mathrm{H}^{+} \cdot 24 \mathrm{C} 8$ are compared to the UVPD spectrum of dBAM $\cdot \mathrm{H}^{+}$(Fig. 5a). The $(0,0)$ band of dBAM $\cdot \mathrm{H}^{+} \cdot 18 \mathrm{C} 6$ is located at $37480 \mathrm{~cm}^{-1}, 30 \mathrm{~cm}^{-1}$ blueshifted from $\mathrm{dBAM} \cdot \mathrm{H}^{+}$and the overall structure of the spectrum is very similar to that of $\mathrm{dBAM} \cdot \mathrm{H}^{+}$except that higher vibronic bands are broadened. This situation is the same as that between aniline $\cdot \mathrm{H}^{+}$and aniline $\cdot \mathrm{H}^{+} \cdot 18 \mathrm{C} 6$. The UVPD spectrum of $\mathrm{dBAM} \cdot \mathrm{H}^{+} \cdot 24 \mathrm{C} 8$ is much weaker and broader and its band origin is located at around $37590 \mathrm{~cm}^{-1}$. Thus, the difference in the complex structure between dBAM $\cdot \mathrm{H}^{+} \cdot 18 \mathrm{C} 6$ and dBAM $\cdot \mathrm{H}^{+} \cdot 24 \mathrm{C} 8$ is not reflected in the electronic transition origins, which are almost the same, but in the width of the vibronic structures. However, the main difference is observed in the UV photofragmentation yield. The right panels of Fig. $5 \mathrm{~b}$ and $\mathrm{c}$ show the TOF spectra of dBAM $\cdot \mathrm{H}^{+} \cdot 18 \mathrm{C} 6$ and dBAM $\cdot \mathrm{H}^{+} \cdot 24 \mathrm{C} 8$ with and without the photodissociation laser, the UV frequency being fixed at the band origin of each complex. By comparing the two TOF spectra, the relative fragmentation yield giving dBAM $\cdot \mathrm{H}^{+}$from dBAM $\cdot \mathrm{H}^{+} \cdot 18 \mathrm{C} 6$ is much larger than that from $\mathrm{dBAM} \cdot \mathrm{H}^{+} \cdot 24 \mathrm{C} 8$ under the same UV laser power conditions. Since the UV absorption cross-sections are similar between $\mathrm{dBAM} \cdot \mathrm{H}^{+} \cdot 18 \mathrm{C} 6$ (a calculated oscillator strength of $1.4 \times 10^{-3}$ ) and dBAM $\cdot \mathrm{H}^{+} \cdot 24 \mathrm{C} 8$ complexes (an oscillator strength $2 \times 10^{-3}$ ), the small fragmentation yield in the latter case is assigned to a barrier for releasing $\mathrm{dBAM} \cdot \mathrm{H}^{+}$from the $24 \mathrm{C} 8$ cavity in the $\mathrm{dBAM} \cdot \mathrm{H}^{+} \cdot 24 \mathrm{C} 8$ pseudo-rotaxane.

It is very difficult to determine the structures of dBAM $\cdot \mathrm{H}^{+} \cdot 18 \mathrm{C} 6$ and dBAM $\cdot \mathrm{H}^{+} \cdot 24 \mathrm{C} 8$ from the electronic spectra. However, the number of possible isomers should be reduced because of the low temperature of the trap ( $30 \mathrm{~K})$. Actually, as shown in Fig. $5 \mathrm{~b}$, the UVPD spectrum of dBAM $\cdot \mathrm{H}^{+} \cdot 18 \mathrm{C} 6$ shows a single sharp band origin. Thus, by assuming that the oscillator strengths of the conformers are not very different from each other, only one major conformer is observed under the present conditions. Fig. 6 shows typical ground state optimized structures of (a) dBAM $\cdot \mathrm{H}^{+} \cdot 18 \mathrm{C} 6$ and (b) dBAM $\cdot \mathrm{H}^{+} \cdot 24 \mathrm{C} 8$. For dBAM $\cdot \mathrm{H}^{+} \cdot 18 \mathrm{C} 6$, a twisted shape $\mathrm{dBAM} \cdot \mathrm{H}^{+}$is attached above $18 \mathrm{C} 6$ and bound to two ether oxygen atoms via $\mathrm{NH} \cdots \mathrm{O}$ H-bonds. In the dBAM $\cdot \mathrm{H}^{+} \cdot 24 \mathrm{C} 8$ complex, on the other hand, dBAM $\cdot \mathrm{H}^{+}$goes through the $24 \mathrm{C} 8$ cavity forming pseudo-rotaxane. The calculated binding energy is $236 \mathrm{~kJ} \mathrm{~mol}{ }^{-1}$ for $\mathrm{dBAM} \cdot \mathrm{H}^{+} \cdot 18 \mathrm{C} 6$, and $264 \mathrm{~kJ} \mathrm{~mol}{ }^{-1}$ for

(a)

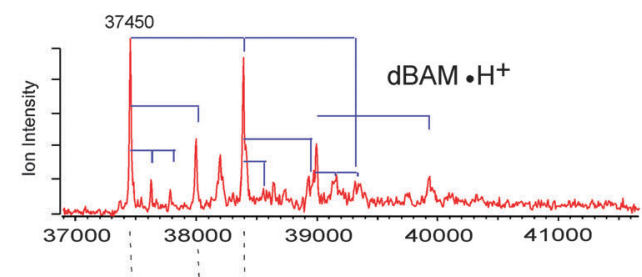

(b)
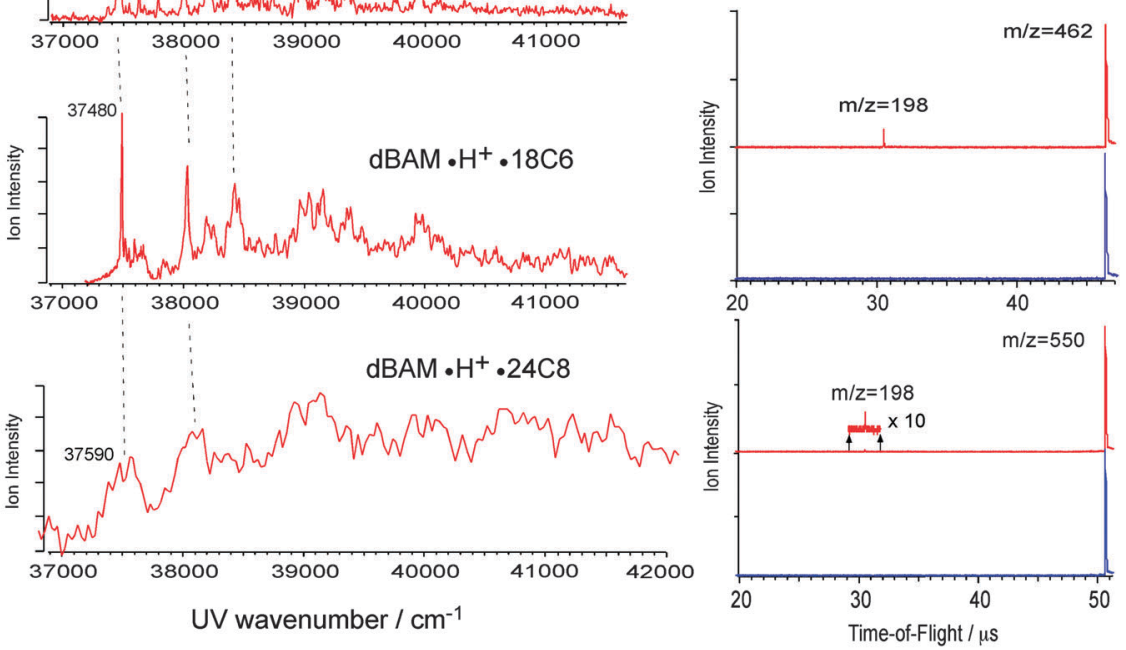

Fig. 5 (a) UVPD spectrum of dBAM. $\mathrm{H}^{+}$. (b) (left) UVPD spectrum of dBAM $\cdot \mathrm{H}^{+} \cdot 18 \mathrm{C} 6$. (right) TOF spectrum without UV irradiation (blue) and with UV fixed at $37481 \mathrm{~cm}^{-1}$ (red). The ion intensity is normalized relative to parent ion intensity. (c) (left) UVPD spectrum of dBAM. $H^{+} \cdot 24 C 8$. (right) TOF spectrum without UV irradiation (blue) and with UV fixed at $37594 \mathrm{~cm}^{-1}$ (red). The ion intensity is normalized relative to parent ion intensity. 


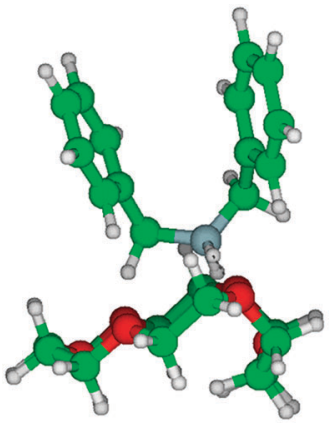

(a) $\mathrm{dBAM} \cdot \mathrm{H}^{+} \cdot 18 \mathrm{C} 6$

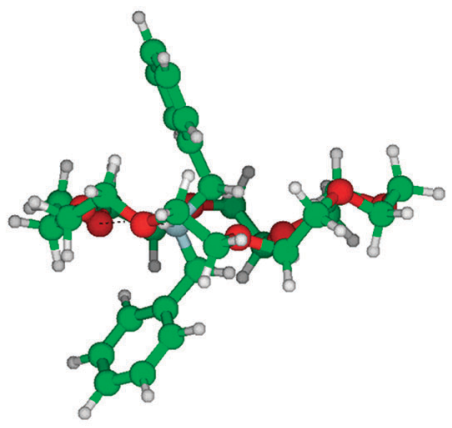

(b) $\mathrm{dBAM} \cdot \mathrm{H}^{+} \bullet 24 \mathrm{C} 8$
Fig. 6 Optimized structures of (a) dBAM $\cdot \mathrm{H}^{+} \cdot 18 \mathrm{C} 6$ and (b) dBAM $\cdot \mathrm{H}^{+} \cdot 24 \mathrm{C} 8$ complexes at the M05-2X/6-31+G* level of calculation.

$\mathrm{dBAM} \cdot \mathrm{H}^{+} \cdot 24 \mathrm{C} 8$ at the $\mathrm{M} 05-2 \mathrm{X} / 6-31+\mathrm{G}^{*}$ level using BSSE corrections. Thus, though the binding energy is not so different between dBAM $\cdot \mathrm{H}^{+} \cdot 18 \mathrm{C} 6$ and $\mathrm{dBAM} \cdot \mathrm{H}^{+} \cdot 24 \mathrm{C} 8$, the low fragmentation yield of $\mathrm{dBAM} \cdot \mathrm{H}^{+} \cdot 24 \mathrm{C} 8$ may come from a larger barrier for $\mathrm{dBAM} \cdot \mathrm{H}^{+}$to be released from the $24 \mathrm{C} 8$ cavity.

\section{4. $\mathrm{dBAM} \cdot \mathrm{H}^{+} \cdot \mathrm{DB} 24 \mathrm{C} 8$ pseudo-rotaxane}

Fig. 7b shows the UVPD spectrum of dBAM $\cdot \mathrm{H}^{+} \cdot \mathrm{DB} 24 \mathrm{C} 8$ pseudorotaxane recorded at $30 \mathrm{~K}$. The spectrum is compared with that of dBAM $\cdot \mathrm{H}^{+}$(Fig. 7a), and DB24C8. $\mathrm{H}^{+}$(Fig. 7c), respectively. The spectrum of $\mathrm{dBAM} \cdot \mathrm{H}^{+} \cdot \mathrm{DB} 24 \mathrm{C} 8$ shows broad structures with a band origin at $\sim 36350 \mathrm{~cm}^{-1}$. It is not clear whether the broadness is due to the overlap of the transitions of several coexisting isomers or to spectral congestion due to low vibrational modes. The first band is more than $1000 \mathrm{~cm}^{-1}$ red-shifted as compared to the $(0,0)$ transition of $\mathrm{dBAM} \cdot \mathrm{H}^{+}$, and is rather close to the $(0,0)$ band of $\mathrm{DB} 24 \mathrm{C} 8 \cdot \mathrm{H}^{+}\left(36050 \mathrm{~cm}^{-1}\right)$. This suggests that the electronic transition of dBAM. $\mathrm{H}^{+} \cdot \mathrm{DB} 24 \mathrm{C} 8$ in this region is not due to $\mathrm{dBAM} \cdot \mathrm{H}^{+}$but to $\mathrm{DB} 24 \mathrm{C} 8$ or $\mathrm{DB} 24 \mathrm{C} 8 \cdot \mathrm{H}^{+}$. For comparison, Fig. 7d shows the laser induced fluorescence spectrum of the $\mathrm{S}_{1}-\mathrm{S}_{0}$ transition of jet-cooled neutral DB24C8 in the band origin region. For neutral DB24C8, two different conformers were identified at 35195 and $35408 \mathrm{~cm}^{-1}$, which were assigned to the chair and boat forms, respectively. ${ }^{21}$ The $S_{1}-S_{0}$ electronic transition of $\mathrm{DB} 24 \mathrm{C} 8 \cdot \mathrm{H}^{+}$is roughly $800 \mathrm{~cm}^{-1}$ blueshifted with respect to that of neutral DB24C8. Thus, the spectrum of $\mathrm{dBAM} \cdot \mathrm{H}^{+} \cdot \mathrm{DB} 24 \mathrm{C} 8$ in this region is assigned to excitation of the DB24C8 $\cdot \mathrm{H}^{+}$chromophore. The intensity of the $\mathrm{dBAM} \cdot \mathrm{H}^{+}$fragment at $m / z=198$ from the $\mathrm{dBAM} \cdot \mathrm{H}^{+} \cdot \mathrm{DB} 24 \mathrm{C} 8$ photodissociation is $10-20$ times larger than that from the $\mathrm{dBAM} \cdot \mathrm{H}^{+} \cdot 24 \mathrm{C} 8$ photodissociation although these complexes have similar pseudo-rotaxane structures. The difference due to the larger absorption cross-section of the DB24C $8 \cdot \mathrm{H}^{+}$chromophore as compared to the $\mathrm{dBAMH}^{+}$absorption will be discussed later (Table 2).

We calculated possible initial structures of DB24C $8 \cdot \mathrm{H}^{+}$and dBAM $\cdot \mathrm{H}^{+} \cdot \mathrm{DB} 24 \mathrm{C} 8$ by MMF calculations further optimized by DFT calculations at the M05-2X/6-31+G* level. Fig. 8 shows the two most stable structures of DB24C $8 \cdot \mathrm{H}^{+}$. Other conformers are more than $2.6 \mathrm{~kJ} \mathrm{~mol}^{-1}$ higher in energy and their structures are shown in Fig. S3 (ESI $\dagger$ ). In isomer 1, a proton is bound in a bifurcated manner to two ether oxygen atoms, one of which is adjacent to a benzene ring. Isomer 2 has a covalent $\mathrm{O}-\mathrm{H}^{+}$bond and the proton is $\mathrm{H}$-bonded to an opposite ether oxygen.

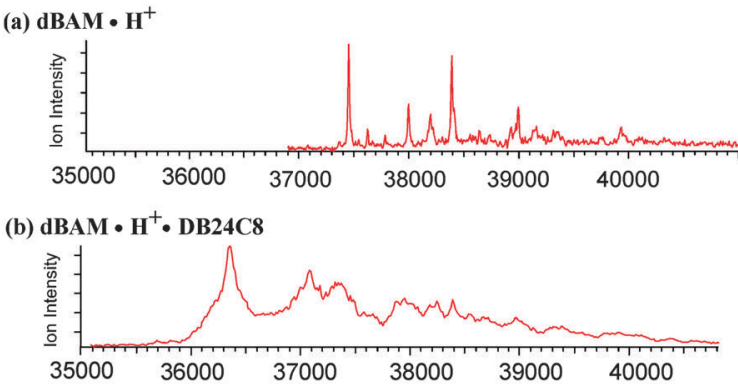

(c) $\mathrm{DB} 24 \mathrm{C} 8 \cdot \mathrm{H}^{+}$
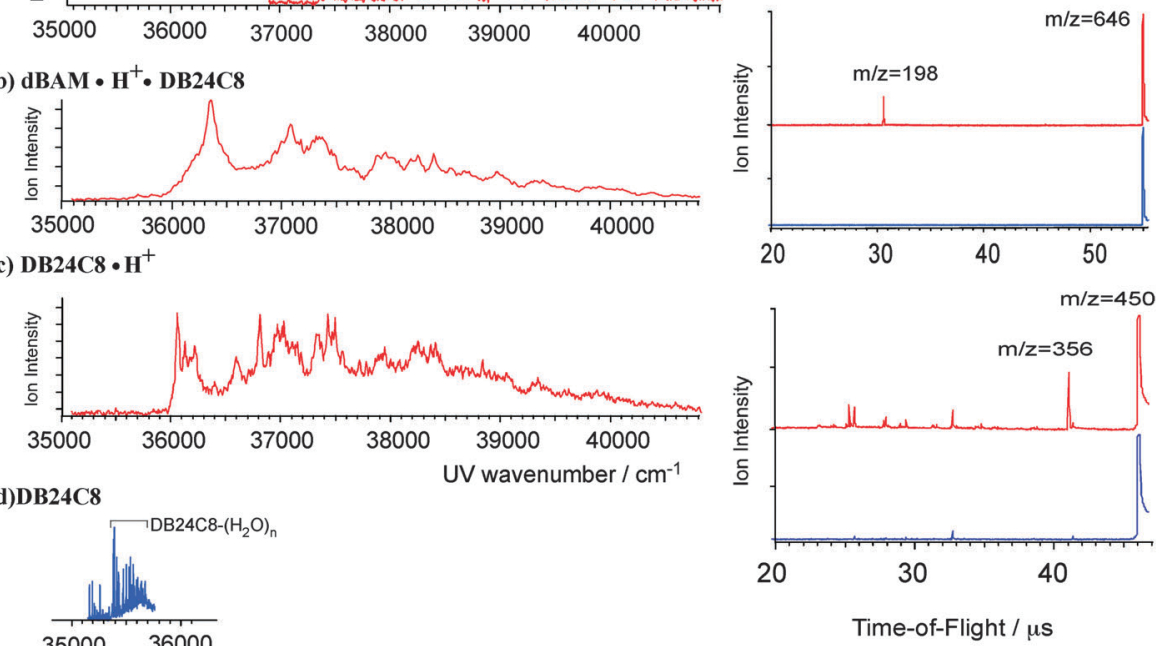

(d)DB24C8

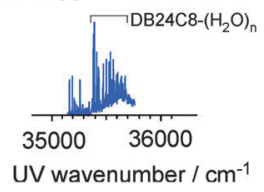

Fig. 7 (a) UVPD spectrum of dBAM. $H^{+}$. (b) (left) UVPD spectrum of dBAM. $H^{+}$.DB24C8. (right) TOF spectrum of dBAM. $H^{+}$.DB24C8 without UV irradiation (blue) and with UV fixed at $36350 \mathrm{~cm}^{-1}$ (red). The ion intensity is normalized relative to parent ion intensity. (c) (left) UVPD spectrum of DB24C8. $\mathrm{H}^{+}$ observed by monitoring $\mathrm{m} / \mathrm{z}=356$ fragment ions. (right) TOF spectrum of DB24C $8 \cdot \mathrm{H}^{+}$without UV irradiation (blue) and with UV fixed at $36050 \mathrm{~cm}{ }^{-1}$ (red). The intensity of DB24C8. $\mathrm{H}^{+}$is largely out of scale to expand the weak fragment ion signals. (d) LIF spectrum of DB24C8 in a supersonic jet. 
Table 2 Vertical excitation energies (eV) and oscillator strengths (parentheses) of dBAM $\cdot \mathrm{H}^{+}, \mathrm{DB} 24 \mathrm{C} 8, \mathrm{DB} 24 \mathrm{C} 8 \cdot \mathrm{H}^{+}$and $\mathrm{dBAM} \cdot \mathrm{H}^{+} \cdot \mathrm{DB} 24 \mathrm{C} 8 \mathrm{rotaxane}$ calculated at the M05-2X/6-31+G* level

\begin{tabular}{|c|c|c|c|c|}
\hline & dBAM$\cdot \mathrm{H}^{+}$(open) & DB24C8 & $\mathrm{DB} 24 \mathrm{C} 8 \cdot \mathrm{H}^{+}$ & $\mathrm{dBAM} \cdot \mathrm{H}^{+} \cdot \mathrm{DB} 24 \mathrm{C} 8$ \\
\hline
\end{tabular}

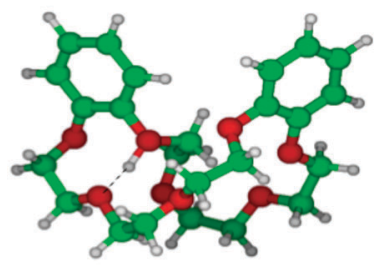

Isomer $1(0 \mathrm{~kJ} / \mathrm{mol})$

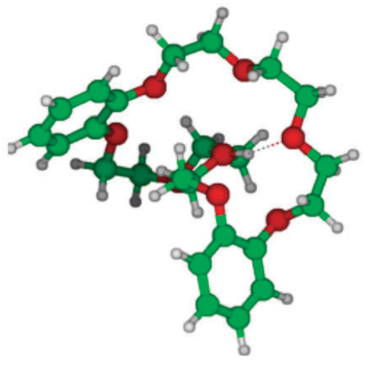

Isomer $2(1.39 \mathrm{~kJ} / \mathrm{mol})$

Fig. 8 Two lowest energy isomers of DB24C $8 \cdot \mathrm{H}^{+}$obtained at the M05-2X/6-31+G* level of calculation. Hydrogen-bonds are shown as dotted lines.

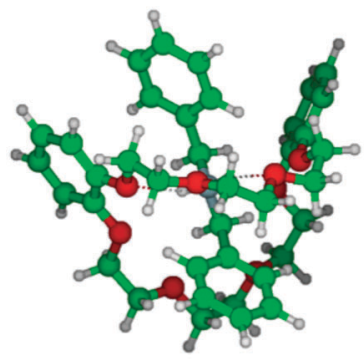

Side View

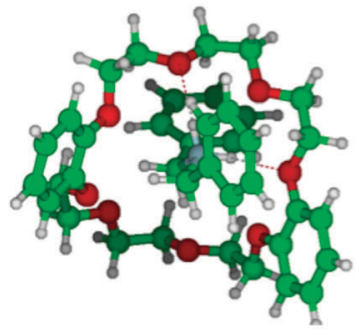

Top View
Fig. 9 Most stable structure of dBAM $\cdot \mathrm{H}^{+}$.DB24C8 pseudo-rotaxane obtained at the M05-2X/6-31+G* level of calculation. Hydrogen bonds between $\mathrm{NH}$ and oxygen atoms of CEs are shown as dotted lines.

The DB24C8 $\cdot \mathrm{H}^{+} \mathrm{S}_{1}-\mathrm{S}_{0}$ electronic transition is more than $800 \mathrm{~cm}^{-1}$ blue-shifted as compared to the neutral DB24C8 transition, which is compatible with the structure of isomer 1 , because its electronic transition should be most affected by the proton binding to the oxygen atom adjacent to one benzene ring in this structure. Fig. 9 shows the most stable structure calculated for the dBAM $\cdot \mathrm{H}^{+} \cdot \mathrm{DB} 24 \mathrm{C} 8$ complex. The next stable isomer is more than $5 \mathrm{~kJ} \mathrm{~mol}^{-1}$ higher in energy (see Fig. S4 in the ESI $\dagger$ ). In the most stable structure, DB24C8 has a boat-structure and the benzene rings form quasi $\pi-\pi$ stacking structure with one of the dBAM benzene rings. In addition, one $\mathrm{NH}$ bond of $\mathrm{dBAM}$ is $\mathrm{H}$-bonded to an oxygen atom adjacent to a DB24C8 benzene ring. This situation is essentially the same as in the most stable structure (isomer 1) of DB24C8 $\cdot \mathrm{H}^{+}$.

The vertical excitation energies and oscillator strengths for the most stable structures of dBAM $\cdot \mathrm{H}^{+}$, neutral DB24C8, DB24C8 $\cdot \mathrm{H}^{+}$ and $\mathrm{dBAM} \cdot \mathrm{H}^{+} \cdot \mathrm{DB} 24 \mathrm{C} 8$ obtained at the M05-2X/6-31+G* level are compared in Table 2. When we compare the $S_{1}-S_{0}$ electronic transition energies of DB24C8, DB24C8 $\cdot \mathrm{H}^{+}$, and $\mathrm{dBAM} \cdot \mathrm{H}^{+}$, we see that those of DB24C8. $\mathrm{H}^{+}$are located between those of $\mathrm{DB} 24 \mathrm{C} 8$ and $\mathrm{dBAM} \cdot \mathrm{H}^{+}$, which is in good agreement with the observed relationship of the UVPD spectra shown in Fig. 7. In addition, the $\mathrm{S}_{1}-\mathrm{S}_{0}$ and $\mathrm{S}_{2}-\mathrm{S}_{0}$ oscillator strengths of DB24C8 $\cdot \mathrm{H}^{+}$are $\sim 5$ times larger than the $\mathrm{dBAM} \cdot \mathrm{H}^{+}$oscillator strength, which also agrees with the observed larger photo-fragmentation yield of $\mathrm{dBAM} \cdot \mathrm{H}^{+} \cdot \mathrm{DB} 24 \mathrm{C} 8$ as compared to that of dBAM $\cdot \mathrm{H}^{+} \cdot 24 \mathrm{C} 8$.

\section{Conclusions}

In summary, we investigated the geometrical and electronic structures of the complex ions of protonated aniline (aniline $\cdot \mathrm{H}^{+}$) and dibenzylamine (dBAM $\cdot \mathrm{H}^{+}$) with crown ethers (CEs) of different cavity sizes, 15C5, 18C6, 24C8, and DB24C8. The aniline $\cdot \mathrm{H}^{+}$complexes with 15C5 and 18C6 have a structure in which the proton is located on the aniline part. After UV excitation, the complexes relax to the ground electronic state and the proton is transferred from the aniline part to the CE moiety producing the protonated CE fragments. The cage effect here completely removes the dissociation channels of the aniline $\cdot \mathrm{H}^{+}$moiety, which is different from what was observed for the tryptamine $\cdot \mathrm{H}^{+} \cdot 18 \mathrm{C} 6$ complex. In addition, the UV spectrum of aniline $\cdot \mathrm{H}^{+}$. CEs is very sensitive to the symmetry of CEs; aniline $\cdot \mathrm{H}^{+} \cdot 18 \mathrm{C} 6$ shows a sharp electronic spectrum similar to aniline $\cdot \mathrm{H}^{+}$, while that of aniline $\cdot \mathrm{H}^{+} \cdot 15 \mathrm{C} 5$ shows very broad structure with poor Franck-Condon factors.

For the $\mathrm{dBAM} \cdot \mathrm{H}^{+}$complexes with CEs, the proton is always located on dBAM. However, CEs have a role of a proton acceptor, leading to the blue-shift of electronic transition. Actually, in the case of DB24C8, the transition of the DB24C8 moiety of dBAM $\cdot \mathrm{H}^{+} \cdot \mathrm{DB} 24 \mathrm{C} 8$ is $\sim 800 \mathrm{~cm}^{-1}$ blue-shifted compared to neutral DB24C8.

A large difference in the fragmentation yield between $\mathrm{dBAM} \cdot \mathrm{H}^{+} \cdot 18 \mathrm{C} 6$ and $\mathrm{dBAM} \cdot \mathrm{H}^{+} \cdot 24 \mathrm{C} 8$ was found due to a large barrier for releasing $\mathrm{dBAM} \cdot \mathrm{H}^{+}$from the axis of rotaxane. Whereas in $\mathrm{dBAM} \cdot \mathrm{H}^{+} \cdot 24 \mathrm{C} 8$ the excitation is on the $\mathrm{dBAMH}^{+}$moiety, in $\mathrm{dBAM} \cdot \mathrm{H}^{+} \cdot \mathrm{DB} 24 \mathrm{C} 8$ the initial excitation is on the $\mathrm{DB} 24 \mathrm{C} 8 \mathrm{H}^{+}$ part and the fragmentation yield is larger in the latter case due to a larger oscillator strength. For further details on the structure of the complexes including the position of the proton, the IR spectrum in the $\mathrm{NH}$ and $\mathrm{OH}$ region should be recorded, which will be the future work.

\section{Acknowledgements}

This study was supported in part by the France-Japan Collaboration Program (SAKURA), the Japan Society for Promotion of Science and 
the ANR Research Grant (ESPEM-ANR2010BLANC040501). We acknowledge the use of the computing facility cluster GMPCS of the LUMAT federation (FR LUMAT 2764).

\section{References}

1 C. J. Pedersen, J. Am. Chem. Soc., 1967, 89, 7017-7036.

2 C. J. Pedersen, Science, 1988, 241, 536-540.

3 A. M. Stuart and J. A. Vidal, J. Org. Chem., 2007, 72, 3735-3740.

4 N. Jose, S. Sengupta and J. K. Basu, J. Mol. Catal. A: Chem., 2009, 309, 153-158.

5 J. Malval, I. Gosse, J. Morand and R. Lapouyade, J. Am. Chem. Soc., 2002, 124, 904-905.

6 R. M. Uda, T. Matsui, M. Oue and K. Kimura, J. Inclusion Phenom. Macrocyclic Chem., 2005, 51, 111-114.

7 I. F. Uchegbu and S. P. Vyas, Int. J. Pharm., 1998, 172, 33-70.

8 L. Tavano, R. Muzzalupo, S. Trombino, I. Nicotera, C. O. Rossi and C. L. Mesa, Colloids Surf., B, 2008, 61, 30-38.

9 R. M. Izatt, J. H. Rytting, D. P. Nelson, B. L. Hayamore and J. J. Christensen, Science, 1969, 164, 443-444.

10 R. M. Izatt, D. P. Nelson, J. H. Rytting and J. J. Christensen, J. Am. Chem. Soc., 1971, 93, 1619-1623.

11 C. J. Pedersen and H. K. Frensdorff, Angew. Chem., Int. Ed., 1972, 11, 16-25.

12 R. M. Izatt, R. E. Terry, B. L. Haymore, L. D. Hansen, N. K. Dalley, A. G. Avondet and J. J. Christensen, J. Am. Chem. Soc., 1976, 98, 7620-7626.

13 R. M. Izatt, R. E. Terry, D. P. Nelson, Y. Chan, D. J. Eatough, J. S. Bradshaw, L. D. Hansen and J. J. Christensen, J. Am. Chem. Soc., 1976, 98, 7626-7630.

14 J. D. Lamb, R. M. Izatt, C. S. Swain and J. J. Christensen, J. Am. Chem. Soc., 1980, 102, 475-479.

15 S. Maleknia and J. Brodbelt, J. Am. Chem. Soc., 1992, 114, 4295-4298.

16 M. B. More, D. Ray and P. B. Armentrout, J. Am. Chem. Soc., 1999, 121, 417-423.

17 J. D. Anderson, E. S. Paulsen and D. V. Dearden, Int. J. Mass Spectrom., 2003, 227, 63-76.

18 R. Kusaka, Y. Inokuchi and T. Ebata, Phys. Chem. Chem. Phys., 2007, 9, 4452-4459.

19 R. Kusaka, Y. Inokuchi and T. Ebata, Phys. Chem. Chem. Phys., 2008, 10, 6238-6244.

20 R. Kusaka, Y. Inokuchi and T. Ebata, Phys. Chem. Chem. Phys., 2009, 11, 9132-9140.

21 S. Kokubu, R. Kusaka, Y. Inokuchi, T. Haino and T. Ebata, Phys. Chem. Chem. Phys., 2010, 12, 3559-3565.

22 R. Kusaka, Y. Inokuchi, S. S. Xantheas and T. Ebata, Sensors, 2010, 10, 3519-3548.

23 R. Kusaka, S. Kokubu, Y. Inokuchi, T. Haino and T. Ebata, Phys. Chem. Chem. Phys., 2011, 13, 6827-6836.

24 R. Kusaka, Y. Inokuchi, T. Haino and T. Ebata, J. Phys. Chem. Lett., 2012, 3, 1414-1420.

25 Y. Inokuchi, O. V. Boyarkin, R. Kusaka, T. Haino, T. Ebata and T. R. Rizzo, J. Am. Chem. Soc., 2011, 133, 12256-12263.
26 Y. Inokuchi, O. V. Boyarkin, R. Kusaka, T. Haino, T. Ebata and T. R. Rizzo, J. Phys. Chem. A, 2012, 116, 4057-4068.

27 Y. Inokuchi, T. Ebata, T. R. Rizzo and O. V. Boyarkin, J. Am. Chem. Soc., 2014, 136, 1815-1824.

28 G. Féraud, M. Broquier, C. Dedonder-Lardeux, G. Grégoire, S. Soorkia and C. Jouvet, Phys. Chem. Chem. Phys., 2014, 16, 5250-5259.

29 J.-P. Desvergne and H. Bouas-Laurent, J. Chem. Soc., Chem. Commun., 1978, 403-404.

30 I. Yamashita, M. Fujii, T. Kaneda, S. Misumi and T. Otsubo, Tetrahedron Lett., 1980, 21, 541-544.

31 H. Bouas-Laurent, A. Castellan and J.-P. Desvergne, Pure Appl. Chem., 1980, 52, 2633-2648.

32 S. Shinkai, T. Nakaji, Y. Nishida, T. Ogawa and O. Manabe, J. Am. Chem. Soc., 1980, 102, 5860-5865.

33 V. Serreli, C.-F. Lee, E. R. Kay and D. A. Leigh, Nature, 2007, 445, 523-527.

34 P. L. Anelli, N. Spencer and J. F. Stoddart, J. Am. Chem. Soc., 1991, 113, 5131-5133.

35 R. A. Bissell, E. Córdova, A. E. Kaifer and J. F. Stoddart, Nature, 1994, 369, 133-137.

36 C. A. Schalley, K. Beizai and F. Vögtle, Chem. Res., 2001, 34, 465-476.

37 I. Alata, J. Bert, M. Broquier, C. Dedonder, G. Feraud, G. Gregoire, S. Soorkia, E. Marceca and C. Jouvet, J. Phys. Chem. A, 2013, 117, 4420-4427.

38 G. Féraud, C. Dedonder, C. Jouvet, Y. Inokuchi, T. Haino, R. Sekiya and T. Ebata, J. Phys. Chem. Lett., 2014, 5, 1236-1240.

39 X. B. Wang and L. S. Wang, Rev. Sci. Instrum., 2008, 79, 073108.

40 C. M. Choi, D. H. Choi, N. J. Kim and J. Heo, Int. J. Mass Spectrom., 2012, 314, 18-21.

41 J. U. Andersen, P. Hvelplund, S. B. Nielsen, S. Tomita, H. Wahlgreen, S. P. Møller, U. V. Pedersen, J. S. Forster and T. J. D. Jørgensen, Rev. Sci. Instrum., 2002, 73, 1284-1287.

42 M. J. S. Dewar, E. G. Zoebisch, E. F. Healy and J. J. P. Stewart, J. Am. Chem. Soc., 1985, 107, 3902-3909.

43 F. Mohamadi, N. G. J. Richard, W. C. Guida, R. Liskamp, M. Lipton, C. Caufield, G. Chang, T. Hendrickson and W. C. Still, J. Comput. Chem., 1990, 11, 440-467.

44 T. A. Halgren, J. Comput. Chem., 1999, 20, 720-729.

45 E. Polak and G. Ribiere, Rev. Fr. Inf. Rech. Oper., 1969, 16, 241-254.

46 M. J. Frisch, G. W. Trucks, H. B. Schlegel, G. E. Scuseria, M. A. Robb, J. R. Cheeseman, G. Scalmani, V. Barone, B. Mennuchi and G. Petersson, et al., Gaussian 09, Revision A.1, Gaussian, Inc., Wallingford, CT2009.

47 P. R. Ashton, E. J. T. Chrystal, P. T. Glink, S. Menzer, C. Schiavo, N. Spencer, J. F. Stoddart, P. A. Tasker, A. J. P. White and D. J. Williams, Chem. - Eur. J., 1996, 2, 709-728.

48 N. Mikami, A. Hiraya, I. Fujiwara and M. Ito, Chem. Phys. Lett., 1980, 74, 531-535.

49 S. Ishikawa, T. Ebata, H. Ishikawa, T. Inoue and N. Mikami, J. Phys. Chem., 1996, 100, 10531-10535. 
50 The notation for the vibrational modes is adapted from G. Varsanyi, Assignments for Vibrational Spectra of Seven Hundreds Benzene Derivatives, Adam Hilger, London, 1974.

51 NIST Chemistry Webbook, NIST Standard Reference Database Number 69, http://webbbok.nist.gov./chemistry/.

52 F. M. Pasker, N. Solca and O. Dopfer, J. Phys. Chem. A, 2006, 110, 12793-12804.
53 H. Kang, C. Jouvet, C. Dedonder-Lardeux, S. Martrenchard, C. Charriere, G. Gregoire, C. Desfrancois, J.-P. P. Schermann, M. Barat, J. A. Fayeton, G. Grégoire and C. Desfrançois, J. Chem. Phys., 2005, 122, 084307.

54 U. Kadhane, M. Pérot, B. Lucas, M. Barat, J. A. Fayeton, C. Jouvet, A. Ehlerding, M.-B. S. Kirketerp, S. B. Nielsen, J. A. Wyer and H. Zettergren, Chem. Phys. Lett., 2009, 480, 57-61. 